\title{
Temporal downregulation of glial cell line-derived neurotrophic factor (GDNF) in the axotomized adult rat facial nucleus.
}

\author{
Yuhki Nagai, Takashi Ishijima, Kazuyuki Nakajima* \\ Department of Science and Engineering for Sustainable Innovation, Faculty of Science and Engineering, Soka \\ University, Tokyo 192-8577, Japan
}

\begin{abstract}
In our previous study, we reported that the levels of $\mathrm{m} 2$ muscarinic acetylcholine receptor and gammaaminobutyric acid receptor $\alpha 1$ in motoneurons were downregulated in the axotomized adult facial nucleus. These results led us to speculate that the phenomenon was attributable to an interruption of the retrograde supply of glial cell line-derived neurotrophic factor (GDNF). To investigate this possibility, in this study we determined the levels of GDNF in the adult rat axotomized facial nucleus. Western blotting revealed that the amounts of GDNF in the transected facial nucleus significantly decreased from $6 \mathrm{~h}$ to 7 d post-insult and returned to control levels at 3-5 weeks post-insult. Immunohistochemical study of the facial nucleus at $3 \mathrm{~d}$ post-insult indicated that many cells were positively stained by anti-GDNF antibody in the control facial nucleus, but the degree of staining was lower in the axotomized facial nucleus. The anti-GDNF antibody-stained cells in the facial nucleus were almost coincident with the anti-NMDA receptor 3B subunit (NR3B) antibody-positive cells, suggesting that the former were motoneurons. Together, these results demonstrated that GDNF levels in injured facial motoneurons transiently decreased from $6 \mathrm{~h}$ to $7 \mathrm{~d}$ post-insult but subsequently returned to the control levels.
\end{abstract}

Keywords: Axotomy, Facial nucleus, Motoneurons, Glial cell line-derived neurotrophic factor.

Accepted on August 17, 2018

\section{Introduction}

We previously reported that adult rat facial nerve axotomy led to decreased levels of $\mathrm{m} 2$ muscarinic acetylcholine receptor (m2MAchR) and gamma-aminobutyric acid receptor $\alpha 1$ $\left(\mathrm{GABA}_{\mathrm{A}} \mathrm{R} \alpha 1\right)$ in living motoneurons in the ipsilateral nucleus $[1,2]$. This phenomenon allowed us to speculate that these receptors in motoneurons were downregulated due to the deprivation of a specific neurotrophic factor that would be retrogradely transported from the target tissue. In the present study, we focused on glial cell line-derived neurotrophic factor (GDNF) as a possible candidate. The main contributions of GDNF to the motor system are considered to involve its function as a target (muscle)-derived neurotrophic factor [3-5], although GDNF is also produced in non-target tissues/cells, including glial cells.

In the neonatal stage, axotomized facial motoneurons undergo cell death, but the injured motoneurons can be rescued by administration of GDNF [6,7]. Thus, GDNF is considered a survival factor for neonatal motoneurons that is retrogradely transported from facial muscle. On the other hand, in the adult stage transected motoneurons do not die $[1,8]$. However, GDNF administration prevents the reduction of choline acetyltransferase levels in injured motoneurons [7], suggesting that target-derived GDNF functions as a regulator of cellular metabolism/function rather than as a survival factor in adulthood.

We thus predicted that the reduction of $\mathrm{m} 2 \mathrm{MAchR}$ and $\mathrm{GABA}_{\mathrm{A}} \mathrm{R} \alpha \mathrm{l}$ levels in axotomized adult motoneurons is attributable to a deprivation of GDNF. However, we did not know that GDNF contents would change in axotomized facial nucleus or injured motoneurons. In the present study, therefore, we quantitatively investigated GDNF protein levels in the axotomized facial nucleus in a time course experiment.

\section{Materials and Methods}

\section{Reagents and antibodies}

Glial cell line-derived neurotrophic factor (GDNF) from rats (G1401) and anti-human GDNF antibody (G8035) that can detect rat GDNF were purchased from Sigma-Aldrich Japan (Tokyo, Japan). Anti-actin (C-11) antibody (sc-1615) was obtained from Santa Cruz Biotechnology (Santa Cruz, CA). Horseradish peroxidase (HRP)-conjugated anti-goat IgG (sc-2020) was purchased from Santa Cruz Biotechnology.

The antibody against NMDA receptor 3B subunit (NR3B) (ab35677) used for identifying motoneurons was supplied by Abcam (Cambridge, UK). Alexa Fluor 488-conjugated anti- 
goat IgG (A11055) and Alexa Fluor 568-conjugated anti-rabbit IgG (A11036) were obtained from Invitrogen (Carlsbad, CA).

\section{Animals and operation}

8-week-old Wistar rats (three female and three male) were originally purchased from Clea Japan (Tokyo), and the progeny were obtained by home breeding. Only male littermates were chosen and kept on a 12-h daylight cycle ad libitum. At 8 weeks of age, they were subjected to the operation. In total, 36 male rats were used in this study.

The experiments were carried out in accordance with the guidelines laid down by the NIH regarding the care and use of animals, and were approved by the ethics committee of Soka University (approval code: 18005).

The right facial nerves of adult rats were cut at the stylomastoid foramen under diethylether anesthesia, as described previously [1,2]. The left facial nerves were left without any treatment. The rats were reared for 6,12 or $24 \mathrm{~h}$; for 3, 5 or $7 \mathrm{~d}$; or for 2, 3 or 5 weeks, and were decapitated under anaesthesia. The whole brains were removed, frozen on dry ice and stored at $-80^{\circ} \mathrm{C}$ until the facial nuclei were cut out.

\section{Immunoblotting}

The contralateral and ipsilateral facial nuclei were carefully cut out from the frozen brainstem. The cut facial nuclei were solubilized with non-reducing sample buffer $(62.5 \mathrm{mmol} / \mathrm{L}$ Tris- $\mathrm{HCl}$ ( $\mathrm{pH}$ 6.8), 2\% sodium dodecyl sulfate, and 5\% glycerol) and centrifuged at $100,000 \mathrm{~g}$ for $30 \mathrm{~min}$. The supernatant of each facial nucleus was recovered as tissue extract. The protein in the tissue extract was quantified by the method of Lowry et al. [9]. The resultant tissue extract was prepared to contain 10\% 2-mercaptoethanol, and then was subjected to immunoblotting for GDNF $(1: 2000)$ and actin (1:4000). By using authentic rat GDNF, we confirmed that our GDNF-determining system can detect 2 ng rat GDNF per lane in immunoblotting.

\section{Immunohistochemistry}

The brainstem was cut into $20-\mu \mathrm{m}$-thick sections with a cryostat (Leica CM1510; Leica Biosystems, Nussloch, Germany) at the level of the facial nuclei, and the sections were frozen at $-80^{\circ} \mathrm{C}$ until staining.

Immunohistochemistry for GDNF was carried out essentially as described previously [1,2]. Briefly, the cryosections were fixed with $3.7 \%$ paraformaldehyde and treated with acetone. The sections were then blocked with blocking solution containing $0.2 \%$ bovine serum albumin (BSA)/PBS. The cryosections were incubated with anti-GDNF antibody $(1: 100)$ for $16 \mathrm{~h}$. Subsequently, these sections were incubated with Alexa Fluor 488-conjugated anti-goat $\operatorname{IgG}(1: 200)$ for $3 \mathrm{~h}$ at room temperature. After washing, the sections were dehydrated, mounted, and observed by a fluorescent microscope (Eclipse TS100; Nikon, Tokyo).
For dual staining with fluorescence, the cryosections were incubated first with anti-GDNF antibody (1:100) for $16 \mathrm{~h}$ and then with anti-NR3B antibody (1:500) for $16 \mathrm{~h}$ at $4^{\circ} \mathrm{C}$. Subsequently, these sections were incubated with Alexa Fluor 488-conjugated anti-goat IgG (1:200) and Alexa Fluor 568conjugated anti-rabbit IgG $(1: 200)$ for $3 \mathrm{~h}$ at room temperature. The sections were then dehydrated, mounted, and observed by a fluorescent microscope.

\section{Statistical analysis}

The densities of protein bands (GDNF) in immunoblotting were measured by densitometry using ImageJ software $(\mathrm{NIH}$, Bethesda, MD). These densities were expressed as the means \pm SDs of three or four separate experiments. Differences between the contralateral and ipsilateral nuclei were assessed via student's t-test. In all cases, $\mathrm{P}$ values less than 0.05 were considered significant $\left({ }^{*} \mathrm{P}<0.05,{ }^{* *} \mathrm{P}<0.01\right)$.

\section{Results}

\section{GDNF levels in the axotomized facial nucleus}

We investigated GDNF levels in the axotomized facial nucleus from $6 \mathrm{~h}$ to 5 weeks post-insult. Immunoblotting indicated that the levels in the transected facial nucleus began to decrease at $6 \mathrm{~h}$ post-insult and that low levels were sustained until $5 \mathrm{~d}$ post-insult (Figure 1A). At 2 weeks post-insult, the levels in the ipsilateral nucleus appeared to return to the control levels (Figure 1A).

The quantified results indicated that the levels of GDNF in the axotomized facial nucleus at $6 \mathrm{~h}, 12 \mathrm{~h}, 24 \mathrm{~h}, 3 \mathrm{~d}, 5 \mathrm{~d}, 7 \mathrm{~d}, 2 \mathrm{w}$, $3 \mathrm{w}$, and $5 \mathrm{w}$ post-insult were $64.3 \pm 9.7 \%, 49.9 \pm 14.5 \%, 44.6$ $\pm 11.2 \%, 35.0 \pm 4.2 \%, 35.7 \pm 5.3 \%, 55.5 \pm 11.6 \%, 87.9 \pm$ $5.0 \%, 98.2 \pm 4.2 \%$ and $107.6 \pm 5.4 \%$, respectively (Figure 1B). These results indicated that the levels of GDNF in the axotomized nucleus began to significantly decrease from $6 \mathrm{~h}$ after transection and that low values were sustained during 1-5 d post-insult. At 2-5 weeks post-insult, the levels were significantly restored. The changes in GDNF levels in the axotomized facial nucleus during 5 weeks post-insult are summarized in Figure 1C, which shows the transient decrease in GDNF levels in the ipsilateral facial nucleus.

\section{Immunohistochemical study for GDNF protein in the transected facial nucleus}

As shown in Figure 1C, immunoblotting revealed that the levels of GDNF declined to their lowest levels at days 3-5 post-insult. To confirm this result immunohistochemically, we prepared cryosections of the facial nucleus recovered at $3 \mathrm{~d}$ post-insult and compared the levels of GDNF between the control nucleus and the injured nucleus. In the control nucleus, many cells were positively stained with anti-GDNF antibody (Figure 2A, ct), but the degree of the staining was weak in the ipsilateral nucleus (Figure 2A, op), indicating that the levels of GDNF protein were lower in the axotomized facial nucleus 
than in the control nucleus. This immunohistochemical result was consistent with that of immunoblotting (Figure 1).
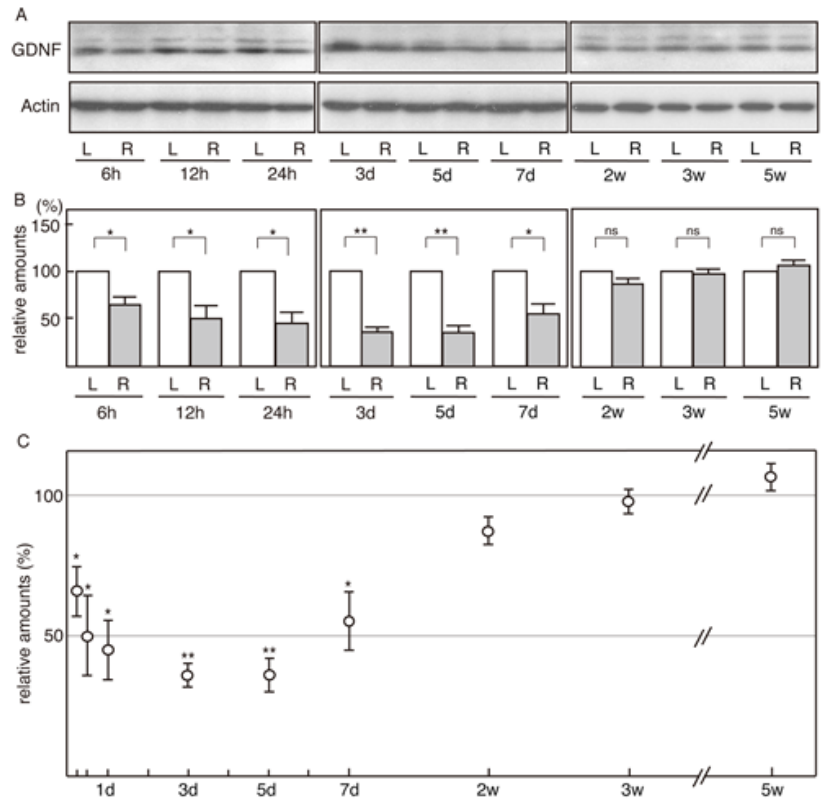

Figure 1. Determination of GDNF levels in the axotomized facial nucleus. (A) Immunoblotting for GDNF: Sets of control (left side: L) and axotomized (right side: $R$ ) facial nuclei recovered at 6,12 and 24 $h(h), 3,5$ and $7 d(d)$ and 2, 3 and 5 weeks (w) after transection were immunoblotted for GDNF and actin (Actin). The results shown are representative of experiments performed in triplicate or quadruplicate; (B) Quantification of GDNF levels: The intensities of the GDNF bands in panel (A) were determined by a densitometer, and the value for the axotomized facial nucleus $(R)$ was expressed relative to that for the control nucleus (L) (defined as 100\%). The data shown are means $\pm S D$ s from three or four independent experiments (ns: Not Significant; $\left.{ }^{*} P<0.05 ;{ }^{* *} P<0.01\right)$; (C) Profile of fluctuation in $G D N F$ levels in the axotomized facial nucleus: Overall results in $B$ are summarized over the time course.

As shown in Figure 2B, the cells stained with anti-GDNF antibody appeared to be motoneurons based on their size and morphology. Thus, to confirm that the GDNF-expressing cells were motoneurons, we double-stained the control facial nucleus at $3 \mathrm{~d}$ post-insult with anti-GDNF antibody and antiNR3B antibody (a motoneuron marker) [10]. The immunohistochemical images revealed that the anti-GDNF antibody-stained cells (Figure 2C, GDNF) were almost coincident with the anti-NR3B-antibody-stained cells (Figure 2C, NR3B). Thus, we confirmed that GDNF protein was present mainly in motoneurons in the facial nucleus.

\section{Discussion}

In the present study, we predicted that a shortage of specific neurotrophic factors caused the reduction of $\mathrm{m} 2 \mathrm{MAchR}$ and $\mathrm{GABA}_{\mathrm{A}} \mathrm{R} \alpha 1$ levels in the axotomized facial nucleus. As candidate factors, we examined GDNF, brain-derived neurotrophic factor (BDNF), neurotrophin-4/5 (NT-4/5), ciliary neurotrophic factor (CNTF) and leukemia inhibitory factor (LIF), because they were previously reported to protect against motoneuron cell death [7,11-14]. Of these, GDNF, BDNF and
NT4/5 have been regarded as target-derived neurotrophic factors. GDNF in particular have been shown to have strong neurotrophic effects on motoneurons at low concentration. In addition, the GDNF protein was actually detected in the tissue extract of rat facial muscle. Considering these facts, we focused on GDNF and tried to clarify the changes in GDNF levels in the injured adult rat facial nucleus.
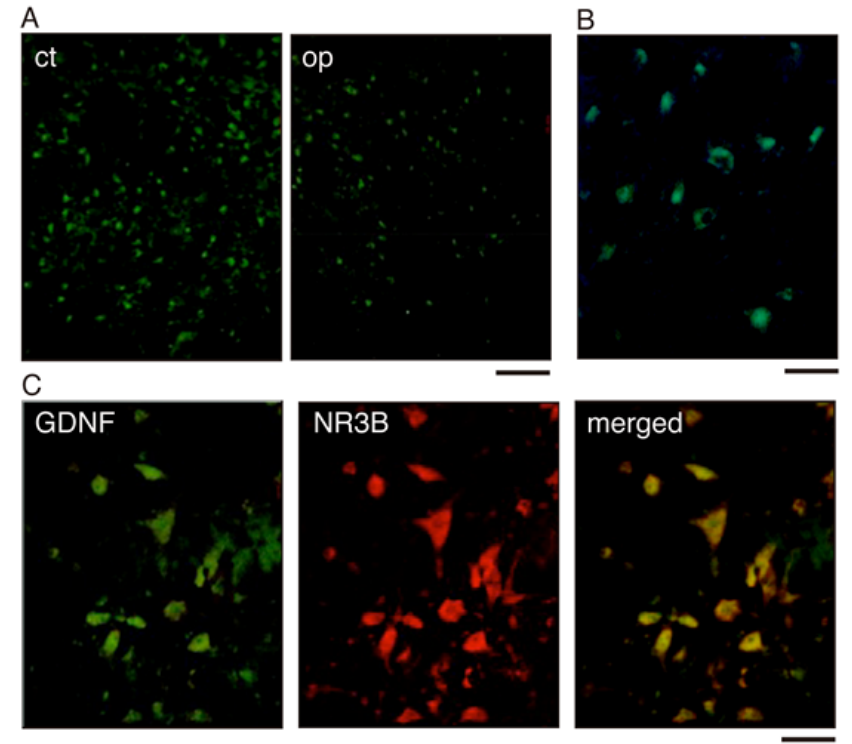

Figure 2. Immunohistochemical analysis of GDNF in the axotomized facial nucleus. (A) Comparison of GDNF levels in both facial nuclei: Brainstem sections obtained at $3 d$ after transection were immunohistochemically stained with anti-GDNF antibody according to a fluorescence method (materials and methods section). Photos of the control nucleus (ct) and operated nucleus (op) were taken by using a 20X objective lens and are shown on the left and right sides, respectively. The scale bar represents $100 \mu \mathrm{m} ;$ (B) Size and morphology of GDNF-expressing cells. Anti-GDNF antibody-staining cells in the control nucleus were taken by using a $40 X$ objective lens. The scale bar represents $50 \mu \mathrm{m}$; (C) Dual staining of the facial nucleus with anti-GDNF and anti-NR3 antibodies. Brainstem sections were dually stained with anti-GDNF antibody and anti$N M D A$ receptor $3 B$ subunit (NR3B) antibody according to fluorescence methods (materials and methods section). In the control facial nucleus at $3 \mathrm{~d}$ post-insult, anti-GDNF antibody-positive cells (GDNF) and anti-NR3B antibody-positive cells (NR3B) were visualized by Alexa Fluor-488 (green) and Alexa Fluor-568 (red), respectively. The merged image is shown on the right-hand side (merged). The scale bar represents $50 \mu \mathrm{m}$.

We found that the levels of GDNF in the lesioned facial nucleus transiently decreased after transection. Statistical analysis indicated that the GDNF level in the ipsilateral nucleus was lowest at 3-5 d post-insult (Figure 1), and after 2 weeks the level returned to that of the control (Figure 1). Our immunohistochemical investigations also supported these results (Figure 2A). This is the first study to investigate GDNF levels in the adult rat axotomized facial nucleus, and the results provided important information concerning the changes in GDNF levels in the injured facial nucleus/motoneurons. Regarding the receptor for GDNF, Burazin et al. [15] reported that GDNFR- $\alpha$ and c-ret mRNAs were upregulated in the axotomized facial nucleus. Their upregulated state suggests 
that the injured motoneurons require much GDNF for their regeneration.

Several reports have described the changing levels of neurotrophic factors/their receptors in the axotomized rat facial nucleus. Kobayashi et al. [16] reported that the protein levels of BDNF and its receptor Trk B increased from $1 \mathrm{~d}$ post-insult in the axotomized rat facial nucleus. Although BDNF is a target-derived neurotrophic factor, in this case the injured motoneurons themselves also produced BDNF. The upregulated BDNF/TrkB levels in the injured motoneurons would contribute to the neuronal repair/regeneration in an autocrine fashion. CNTF [13] and LIF [14] are non-targetderived neurotrophic factors with the ability to rescue injured infant motoneurons. However, it is unknown whether their levels in the axotomized facial nucleus are upregulated or downregulated, because no quantified results have been reported. On the other hand, the levels of CNTF receptor alpha $(\mathrm{CNTFR} \alpha)$ and LIF receptor beta (LIFR $\beta)$ in the axotomized facial nucleus have been analyzed [17]. At an early time point after transection, the levels of CNTFR $\alpha$ mRNA were reduced in the axotomized facial motoneurons, while the levels of LIFR $\beta$ mRNA were increased. However, at 6 weeks postlesion both mRNAs returned to the control levels. From a teleological point of view, we speculate that the injured motoneurons may require much LIF but not CNTF in the early post-lesion period, after which they may require CNTF in addition to LIF for their regeneration. Although there is clearly only limited information regarding the change of neurotrophic factors in the axotomized facial nucleus, it appears that the profile of GDNF in the injured facial nucleus roughly resembles that of CNTFR $\alpha$ mRNA.

We showed here a phenomenon in which amounts of GDNF in the injured facial nucleus are upregulated before the reinnervation of the facial nerve. Injured facial motoneurons have been suggested not to re-innervate target muscle at 7-14 d post-insult [18], in which case they could not directly obtain GDNF from the target tissue at that time. However, as shown in Figure 1B, the levels of GDNF in the axotomized nucleus tended to increase from $7 \mathrm{~d}$ post-insult. From where was GDNF supplied? There are two possibilities. One is that motoneurons themselves enhanced the production of GDNF. A neurotrophin BDNF is known to be enhanced in transected adult rat facial motoneurons after nerve injury [16]. Similar to the case, it is possible that the injured motoneurons promote the production of GDNF after $7 \mathrm{~d}$ post-insult. Another plausible possibility is that glial cells such as microglia and astrocytes around injured motoneurons supply GDNF. Schwann cells at cut nerves might also be able to supply the neurotrophic factor. In such a situation, the injured motoneurons could obtain some amounts of GDNF by enhancing their production of GDNF receptors (GDNFR- $\alpha$ mRNA, c-ret mRNA) [15] and would restore their metabolism and functional state. Glial cells including astrocytes [19,20], microglia [21,22] and Schwann cells $[6,23]$ in vitro have actually been shown to have the ability to express GDNF protein. Thus, there is likelihood that glial cell-derived GDNF is supplied to injured motoneurons in vivo in the adult stage.
In this study, we provided important information about the changes in GDNF levels in the injury/repair processes of motoneurons. We believe that our findings will contribute to an elucidation of the mechanism by which injured adult motoneurons restore their cellular metabolism and function.

\section{Conclusion}

Transection of the adult rat facial nerve led to a transient downregulation of GDNF in the ipsilateral facial nucleus. Injured motoneurons were thought to decrease GDNF levels.

\section{Contributors}

Yuhki Nagai performed the axotomy on the animals and was primarily responsible for analyzing GDNF protein by immunoblotting. Takashi Ishijima prepared the animals for this study and assisted Yuhki Nagai. Kazuyuki Nakajima contributed to the design of the study and carried out immunohistochemistry for GDNF.

\section{Conflict of Interest}

The authors have no conflict of interest to declare.

\section{Funding}

This research was not supported by any grant from funding agencies in the public, commercial, or not-for-profit sectors.

\section{Acknowledgment}

We thank Yoko Tohyama for her very good and careful care of the animals.

\section{References}

1. Ichimiya T, Yamamoto S, Honda Y, Kikuchi R, Kohsaka S, Nakajima K. Functional down-regulation of axotomized rat facial motoneurons. Brain Res 2013; 1507: $35-44$.

2. Kikuchi R, Hamanoue M, Koshimoto M, Kohsaka S, Nakajima K. Response of the GABAergic system to axotomy of the rat facial nerve. Neurochem Res 2018; 43: 324-339.

3. Leitner ML, Molliver DC, Osborne PA, Vejsada R, Golden JP, Lampe PA, Kato AC, Milbrandt J, Johnson EM Jr. Analysis of the retrograde transport of glial cell line-derived neurotrophic factor (GDNF), neurturin, and persephin suggests that in vivo signaling for the GDNF family is GFRalpha coreceptor-specific. J Neurosci 1999; 19: 9322-9331.

4. Lu YY, Wang LJ, Muramatsu S, Ikeguchi K, Fujimoto K, Okada T, Mizukami H, Matsushita T, Hanazono Y, Kume A, Nagatsu T, Ozawa K, Nakano I. Intramuscular injection of AAV-GDNF results in sustained expression of transgenic GDNF, and its delivery to spinal motoneurons by retrograde transport. Neurosci Res 2003; 45: 33-40. 
5. Tomac A, Widenfalk J, Lin LF, Kohno T, Ebendal T, Hoffer BJ, Olson L. Retrograde axonal transport of glial cell line-derived neurotrophic factor in the adult nigrostriatal system suggests a trophic role in the adult. Proc Natl Acad Sci USA 1995; 92: 8274-8278.

6. Henderson CE, Phillips HS, Pollock RA, Davies AM, Lemeulle C, Armanini M, Simmons L, Moffet B, Vandlen RA, Simpson LC corrected to Simmons L, Koliatsos VE, Rosenthal A. GDNF: a potent survival factor for motoneurons present in peripheral nerve and muscle. Science 1994; 266: 1062-1064.

7. Yan Q, Matheson C, Lopez OT. In vivo neurotrophic effects of GDNF on neonatal and adult facial motor neurons. Nature 1995; 373: 341-344.

8. Kreutzberg GW. Microglia: a sensor for pathological events in the CNS. Trends Neurosci 1996; 19: 312-318.

9. Lowry OJ, Rosebrough NJ, Farr AL, Randall RJ. Protein measurement with the Folin phenol reagent. J Biol Chem 1951; 193: 265-275.

10. Matsuda K, Fletcher M, Kamiya Y, Yuzaki M. Specific assembly with the NMDA receptor $3 \mathrm{~B}$ subunit controls surface expression and calcium permeability of NMDA receptors. J Neurosci 2003; 23: 10064-10073.

11. Yan Q, Elliott JL, Matheson C, Sun J, Zhang L, Mu X, Rex KL, Snider WD. Influences of neurotrophins on mammalian motoneurons in vivo. J Neurobiol 1993; 24: 1555-1577.

12. Koliatsos VE, Cayouette MH, Berkemeier LR, Clatterbuck RE, Price DL, Rosenthal A. Neurotrophin 4/5 is a trophic factor for mammalian facial motor neurons. Proc Natl Acad Sci USA 1994; 91: 3304-3308.

13. Gravel C, Götz R, Lorrain A, Sendtner M. Adenoviral gene transfer of ciliary neurotrophic factor and brainderived neurotrophic factor leads to long-term survival of axotomized motor neurons. Nat Med 1997; 3: 765-770.

14. Hughes RA, Sendtner M, Thoenen H. Members of several gene families influence survival of rat motoneurons in vitro and in vivo. J Neurosci Res 1993; 36: 663-671.

15. Burazin TC, Gundlach AL. Up-regulation of GDNFRalpha and c-ret mRNA in facial motor neurons following facial nerve injury in the rat. Brain Res Mol Brain Res 1998; 55: 331-336.

16. Kobayashi NR, Bedard AM, Hincke MT, Tetzlaff W. Increased expression of BDNF and trkB mRNA in rat facial motoneurons after axotomy. Eur J Neurosci 1996; 8: 1018-1029.
17. Haas CA, Hofmann HD, Kirsch M. Expression of CNTF/ LIF-receptor components and activation of STAT3 signaling in axotomized facial motoneurons: evidence for a sequential post-lesional function of the cytokines. J Neurobiol 1999; 41: 559-571.

18. Moran LB, Graeber MB. The facial nerve axotomy model. Brain Res Brain Res Rev 2004; 44: 154-178.

19. Bresjanac M, Antauer G. Reactive astrocytes of the quinolinic acid-lesioned rat striatum express GFRalpha1 as well as GDNF in vivo. Exp Neurol 2000; 164: 53-59.

20. Moretto G, Walker DG, Lanteri P, Taioli F, Zaffagnini S, $\mathrm{Xu} \mathrm{RY}$, Rizzuto N. Expression and regulation of glial-cellline-derived neurotrophic factor (GDNF) mRNA in human astrocytes in vitro. Cell Tissue Res 1996; 286: 257-262.

21. Batchelor PE, Liberatore GT, Wong JY, Porritt MJ, Frerichs F, Donnan GA, Howells DW. Activated macrophages and microglia induce dopaminergic sprouting in the injured striatum and express brainderived neurotrophic factor and glial cell line-derived neurotrophic factor. J Neurosci 1999; 19: 1708-1716.

22. Matsushita Y, Nakajima K, Tohyama Y, Kurihara T, Kohsaka S. Activation of microglia by endotoxin suppresses the secretion of glial cell line-derived neurotrophic factor (GDNF) through the action of protein kinase $\mathrm{C}$ alpha $(\mathrm{PKCa})$ and mitogen-activated protein kinases (MAPKS). J Neurosci Res 2008; 86: 1959-1971.

23. Hoke A, Cheng C, Zochodne DW. Expression of glial cell line-derived neurotrophic factor family of growth factors in peripheral nerve injury in rats. Neuroreport 2000; 11 : $1651-1654$

\section{*Correspondence to}

Kazuyuki Nakajima

Department of Science and Engineering for Sustainable Innovation

Faculty of Science and Engineering

Soka University

Tokyo 192-8577

Japan 